\title{
Individuals, communities, and sound change: an introduction
}

\section{Glossa}

a journal of general linguistics

SPECIAL COLLECTION:

INDIVIDUALS, COMMUNITIES, AND SOUND CHANGE

\section{RESEARCH}

\section{LAUREN HALL-LEW \\ PATRICK HONEYBONE \\ JAMES KIRBY}

*Author affiliations can be found in the back matter of this article

\section{] $u[$ ubiquity press}

CORRESPONDING AUTHOR:

\section{Lauren Hall-Lew}

University of Edinburgh 3 Charles St., Edinburgh, EH8 9AD, GB

Lauren.Hall-Lew@ed.ac.uk

\section{KEYWORDS:}

sound change; language change; individual differences; variation

TO CITE THIS ARTICLE: Hall-Lew, Lauren, Patrick Honeybone and James Kirby. 2021. Individuals, communities, and sound change: an introduction. Glossa: a journal of general linguistics 6(1): 67. 1-17. DOI: https://doi.org/10.5334/ gjgl.1630 


\section{Introduction}

Do individual differences affect sound change? Traditional approaches to phonetic and phonological change typically downplay differences between the individuals who make up a speech community that is undergoing change. Instead, they focus on either the impact of a change on a language's phonological system (which is taken to be homogenous), or on the ways in which a change progresses through distinct social groups within the community. Speakers are generally expected to behave similarly within socially definable groups (with 'structured heterogeneity', following Weinreich, Labov \& Herzog 1968), just as segments are expected to behave similarly within natural classes.

In recent years, however, several distinct traditions of research have questioned these assumptions. They claim, instead, that individual differences between members of a speech community at a psychological, sociological, physiological, genetic, and/or behavioral level, are at least apparent in the innovation and/or propagation of sound change. While there is no doubt that individual differences exist, the key question for us is: to what degree are they crucial to explaining any of the general properties of sound change? The canonical outlier, as in our cover image (given here as Figure 1) is often ignored. But should it be? Could it be an individual initiating a change? Other questions that we ask here include: How strong is the evidence that individuals behave fundamentally differently in the innovation or propagation of change? Do only certain types of individuals ever innovate change, or implement the phonologization of change, or behave differently in acquisition, leading to change? Do differences between individuals determine whether or how they implement or increment change? We think it would be just as important a result to discover that individual differences do not affect sound change as if we discover that they do, or indeed to discover that individual differences are relevant to understanding some aspects or types of change but not others.

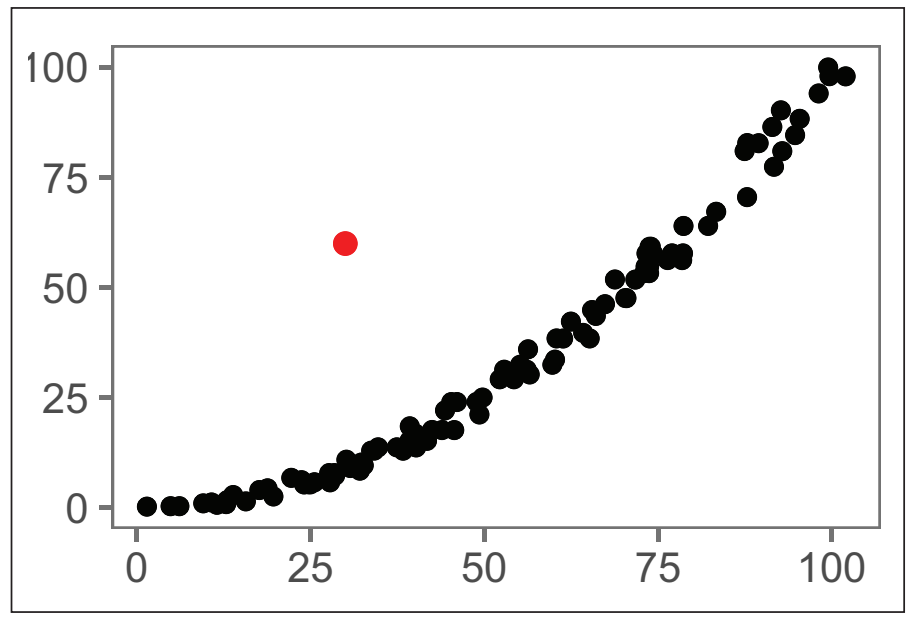

The Glossa Special Collection to which this article is an introduction is all about these questions. We don't think that it answers them all - that would be too much for a single volume to do but it does flag up areas where scholars in different traditions are in fact working on similar issues, as well as places where scholars using similar terminology are actually talking about quite different things. This introduction provides a context for the other articles in this volume, and also serves as a discussion in its own right.

Previous work on these points (e.g., Labov 1979; Sankoff \& Blondeau 2007; Baker, Archangeli \& Mielke 2011; Yu 2013; Stevens \& Harrington 2014; Jones 2015; Yu \& Zellou 2019) has provided insightful overviews of aspects of the topic or results which expand our understanding, but such work tends to focus on one aspect of the whole, e.g., experimental work or sociolinguistic study. A full picture requires us to pull together aspects of theory from phonetics, phonology, sociolinguistics, language modelling, psychology, genetics and language acquisition. Our aim with this piece is to point towards that synthesis. 
The remainder of this article is structured as follows. Section 2 lists the other papers that appear in this Special Collection, and sets them in an initial context. Section 3 considers briefly how we might understand 'sound change', and Section 4 considers what we mean by 'individual differences'. Section 5 summarizes and concludes with an overview of the current research landscape.

\section{The 'Individuals, Communities, and Sound Change' Special Collection}

This Special Collection reflects our shared perspective that while research is typically conducted in separate academic traditions, understanding diachronic change must be a multidisciplinary endeavor. For example, variationist sociolinguistics and language evolution constitute nearly autonomous research communities, but we believe that both have things to tell us about change. Similarly, although deep and sustained interaction between phoneticians and phonologists remains the exception rather than the rule, we think that we cannot hope to understand sound change without considering insights from both. We have written this current piece, and gathered the other articles in the Special Collection, with the aim of initiating and strengthening interaction between these groups. The collected articles bring together a diverse range of researchers, working toward a common understanding of the issues; we hope that this Special Collection will help us to recognize where there are real differences of opinion, and where research results are in fact compatible. In so doing, we hope to establish discussion across disciplinary boundaries, and to reduce tension between the individual-based and community-based approaches to the study of linguistic change. The other pieces in this Special Collection are:

- Ricardo Bermúdez-Otero: The initiation and incrementation of sound change: Communityoriented momentum-sensitive learning

- Dan Dediu \& Scott R. Moisik: Pushes and pulls from below: Anatomical variation, articulation and sound change

- Robin Dodsworth: Bipartite network structures and individual differences in sound change

- Penelope Eckert: The individual in the semiotic landscape

- Laurel MacKenzie: Perturbing the community grammar: Individual differences and communitylevel constraints on sociolinguistic variation

- Bridget J. Smith, Jeff Mielke, Lyra Magloughlin \& Eric Wilbanks: Sound change and coarticulatory variability involving English $/ \mathrm{d}$ /

- Mary Stevens, Jonathan Harrington \& Florian Schiel: Associating the origin and spread of sound change using agent-based modelling applied to /s/-retraction in English

- Alan Yu: Toward an individual-difference perspective on phonologization

Each of the articles began its life as an invited talk at the Fourth International Workshop on Sound Change, which we organized at the University of Edinburgh in 2017. Each piece has developed considerably since then, however, as the authors have responded to both what they heard from the others at the Workshop, and to the reviewers' reports that they received after submitting their articles to Glossa. In the remainder of this piece, we refer to these articles using the authors' surnames in SMALL CAPITALS (other references use the normal 'Author, Date' system).

These papers explore, both separately and as a set, how individual differences relate to community patterns; how they impact variation; and the degree to which they affect the initiation, phonologization, and propagation of change. Some contributions are primarily discursive (BERMÚDEZ-OTERO; ECKERT; MACKENZIE; YU), while others focus more on the reporting of results (DEDIU \& MOISIK; DODSWORTH; STEVENS, HARRINGTON \& SCHIEL; SMITH, MielKe, Magloughlin \& WilbanKs). This introduction fills in some of the gaps around them. In terms of empirical focus, BERMÚDEZ-OTERO, ECKERT and MACKENZIE consider evidence from a number of changes to build their cases, while the other articles focus on one particular change or type of phonetic/phonological phenomenon. Both DEDIU \& MOISIK and SMITH, MielKe, MAgloughlin \& Wilbanks investigate rhotic articulations - DEDIU \& MOISIK from a multi-lingual and multi-ethnic sample, and SMith, MiELKE, MAGLOUGHLIN \& WilbANKS on the basis of data from speakers of North Carolina English, in part focusing on rhotic-influenced 
coarticulations. DODSWORTH also focuses on speakers of North Carolina English, considering their interaction with the Southern Vowel Shift; STEVENS, HARRINGTON \& SCHIEL consider the $\mathrm{s}>\int$ change, largely on the basis of data from Australian English. Finally, Yu considers vowel height-duration interactions, focusing on data from Hong Kong Cantonese.

\section{What is 'sound change'?}

Sound change has been seriously studied for centuries, so it would be hopeless to try to summarize all work on the topic here, or even to discuss all the sound-change-related ideas that have been developed. In spite of this long heritage, however, we need to recognize that we are on shaky ground in talking about 'sound change' at a quite basic level. As Garrett (2015) notes, "[d]espite its ubiquity, there is no generally accepted definition of sound change." One major contrast in ways of understanding 'sound change' is in terms of whether it refers to (i) any kind of change that affects anything relevant to the 'phon' aspect of language or to (ii) only certain types of such change.

The latter usage links to the Neogrammarians' distinction (from the late 19th century) between 'sound change' (Lautwandel), which was expected to be exceptionless, and other kinds of phonologically-relevant change (such as analogy) which could be sporadic. The neogrammarian paradigm has long roots and the heart of it is still a live position in historical phonology (see Hill 2019 and Labov 2020 for recent defenses of the fundamental idea). The notion that a fundamental type of change is 'regular' (or 'exceptionless') links for some theorists to approaches which see one main type of phonological change as involving alterations to a rule-type computational component, while the other type involves the restructuring (or 'reanalysis') of underlying forms.

Such ideas are found in Rule-Based-Phonology-type approaches (as in, for example, King 1969 and Ringe \& Eska 2013) or arguably in any broad-definition-structuralist approach (including Optimality Theory). They have been linked to a 'life cycle of phonological processes' (see, for example, BermúdezOtero 2015, and also BERMÚDEZ-OTERO in this collection) which models phonologization and related developments, in which the early stages are assumed to be exceptionless (and hence count as 'sound change') and later stages (which are closer to morphology or the lexicon) are not (and do not). Others working in this area do not adopt the frameworks of formal phonological theory, but still assume that 'sound change' is regular and/or is closely tied to phonetics.

Whether rule-based or not, in this usage, 'regular sound change' is a tautology, and 'sound change studies' should focus on a specific type of change, which are 'natural' or 'neogrammarian'. ${ }^{1}$ Some kinds of change that affect phonetics and phonology are 'sound change' in this picture, and others (analogies and sporadic borrowings, for example) are not. This two-way split is reminiscent of (but does not simply map onto) the distinction between 'changes from below' and 'changes from above' in the terminology of Labov $(1966,2001)$.

In the more general usage of 'sound change' (which includes any type of change), these latter points need not hold. For example, Bybee talks both about "lexical diffusion in regular sound change", implying that sound change need not be regular, and - indeed - can diffuse through the lexicon gradually (2002a), and also of "phonetically conditioned sound change", implying that sound change need not be phonetically-conditioned (2002b). This illustrates the broader usage of 'sound change', which can include any kind of diachronic change that affects phonetics and/or phonology.

We did not prescribe any interpretation of 'sound change' to the authors of articles in this Special Collection, nor is the 'Workshop on Sound Change', from which the collection ultimately derives, explicit in this regard. Some articles in this collection assume something like the tighter neogrammarian definition of 'sound change' (BERMÚDEZ-OTERO, for example), but not all do (for instance, STEVENS, HARRINGTON \& SCHIEL write that "sound change in the IP-model ... [which they adopt] ... is both phonetically and lexically gradual", rejecting the notion that sound change is regular, and ECKERT is explicit that she is not only interested in things which get labelled as 'change from below'). In considering the broad range of perspectives in this Special Collection, we can thus recognize that, for some scholars, it may be possible in principle to argue that individual 
differences might have no effect in sound change but might have an effect in other types of phonetic or phonological change, whereas for other scholars this claim might make no sense.

A further key point for our purposes is that there is vastly more to understanding sound change than just the issues concerning phonetic and phonological structure that this section has focused on thus far. Much discussion of sound change instead focuses on the social aspect of change. Whether or not a linguist restricts her definition of 'sound change' to only neogrammarian-like changes, a full understanding of change also depends on at least some understanding of the structures of speech communities and the relationship between individual community members and those structures.

While the simplicity of the distinction can be disputed, we assume that it is not possible to understand the field, or possible disagreements within it, unless we recognize both aspects of change, considering both (i) phonetic and phonological structure and (ii) social and community structure; that is, we need to address both the innovation and propagation of change. The terminology used in this area is not agreed $^{2}$ (and authors in this Special Collection vary in this respect); for example, initiation is sometimes used as a synonym for innovation (a speaker-hearer or group might innovate a change or might initiate it, for example). To further complicate things, these two terms are sometimes used with different meanings, with 'an innovation' being a structural difference (of the sort $s>\mathrm{h}$, for example, or a $>$ e) and 'initiation' referring to the very first stage of the process which leads to a change affecting the phonology of a speech community.

Furthermore, some scholars talk of the actuation of change (following Weinreich, Labov \& Herzog 1968) in a way which can overlap (or be synonymous) with this latter usage of initiation, ${ }^{3}$ although this depends, in fact, on each scholar's definition of 'language' - does it reside in individuals or in communities? ${ }^{4}$ If the latter, as Weinreich, Labov \& Herzog themselves argue, then this discussion has already veered away from considering things from a purely structural perspective, because actuation then only occurs when an innovation begins to be taken up by a speech community. Nonetheless, most of the things that we need to understand in order to make sense of innovation are the kinds of things that phoneticians and phonologists work on (e.g., articulation, acoustics, contrast and phonological structures).

Propagation typically requires us to consider the kinds of things that sociolinguists and dialectologists work on (e.g., social characteristics and groupings, identities, geographical and psychogeographical space). Here, too, there is terminological variation. Some use spread as a synonym for 'propagation' (as in 'the spread of an innovation'), ${ }^{5}$ while others use diffusion in this way. This latter term is especially complex, because it can be used in the way just mentioned, or to mean lexical diffusion (in which an innovation is assumed to affect different words at different times, as in Bybee 2002a, b), or to contrast with transmission (as in Labov 2007). In Labovian usage diffusion refers to the acquisition of linguistic structures through contact, principally by adults in contact with other adults, including imperfect acquisition, which can lead to change (while transmission refers to the acquisition of linguistic structures by children in unbroken native-language descent, which can also lead to change through imperfect acquisition).

Terminological issues like these may seem unimportant, but it is crucial to bear them in mind when interpreting what authors write, and - to bring things back to the topic of this Special Collection - when interpreting which aspect of change they are focusing on. It could in principle

2 See Janda \& Joseph (2003), who illustrate the terminological variation by talking of the "inception/onset/ point-of-origin of a change" as alternatives for innovation and of "spread/diffusion" for what we have here called propagation. Croft (2000) is one author who explicitly argues for the use of the terms innovation and propagation (and for the importance of thinking carefully about the distinction). As a further example of the range of terminology in use in this whole area, we can note that the distinction that we have made between 'phonetic and phonological structure' and 'the social aspect of change' is reminiscent of the variationist practice of simultaneously modelling 'internal' and 'external' constraints (e.g., Labov 1994, 2001) and of the distinction between 'endogenous' and 'exogenous' origins of features made in historical linguistics (e.g., Lass 1997).

3 DEDIU \& MOISIK are explicit in distinguishing between initiation and actuation in their conception, unlike, for example, Hansson (2008), who talks of the "initiation (actuation) phase of sound change" (as Stevens \& Harrington 2014 note)

4 This is a massive conceptual disagreement (for example between those who adopt a Chomsky-influenced generative perspective and those who adopt a Labov-influenced sociolinguistic perspective) which has considerable implications for how we conceive of our topic; see also footnote 6, and Section 5.

5 SteVEns, HARRINGTON \& SCHIEL's article in this collection refers to "the origin and spread of sound change", also illustrating the use of origin as another possible synonym for innovation. 
be that individual differences are important in innovation (and/or in the 'initiation' or 'actuation of change') but not in propagation (and/or in 'diffusion through a speech community'), or vice versa. It could potentially be that different scholars see that individual differences are entirely relevant or irrelevant to understanding change because they focus only on one aspect of change. This focus can lead to contradictory and potentially confusing terminological usage. For example, Hale (2007) writes that the:

“... general contrast between change and diffusion must necessarily be maintained if we are to limit our attention to relevant phenomena. That the two types of phenomena really contrast can be seen quite clearly from the fact that changes need not diffuse: it is entirely possible - indeed, in my view, the norm - that many of the differences between a given acquirer's input source grammar(s) and the grammar he or she constructs will never spread to others ...." (2007: 39)

Hale here contrasts 'change' and 'diffusion', which would translate into 'innovation' and 'propagation' in the main terminological pair that we have adopted. Milroy (1992), on the other hand, writes that:

"we can propose [a] distinction ... between speaker innovation on the one hand, and linguistic change on the other. Innovation and change are not conceptually the same thing: an innovation is an act of the speaker, whereas a change is observed within the language system ...." (1992: 169)

Milroy here contrasts 'speaker innovation' and 'change', which would again translate for us to 'innovation' and 'propagation'. The fact that Hale sees innovation as change while Milroy sees propagation as change (for Milroy, like Labov, 'language system' is inherently social) shows that authors with different perspectives can use the same word to mean very different things. This point is relevant to the papers in this Special Collection: YU, for example, "sees language change as a reflection of a difference between the grammars of individuals," and follows Hale in setting aside (although not ignoring) propagation, while STEVENS, HARRINGTON \& SCHIEL discuss at-least-partly speaker-specific "directional phonetic variation that can be converted into sound change", which may separate off what for Yu are the initial stages of an innovation as something that is not sound change itself. We flag this up not to judge who is 'right', but to acknowledge the variation in usage and conception that exists. ${ }^{6}$ Indeed, there is much more to the terminological and conceptual variety of 'sound change studies' than we have been able to consider here ${ }^{7}$ (see Salmons 2021 for an inclusive approach that goes further). Our intent in contemplating all this, and in bringing together the range of authors represented in this Special Collection, is to encourage engagement with all these perspectives.

To place the other articles from this collection in this context, YU focuses on innovations, arguing that we should see phonologization as located in individuals, DEDIU \& MoISIK focus on physiological differences that might lead to innovation ('initiation and actuation'), ${ }^{8}$ and Smith, Mielke, Magloughlin \& Wilbanks also concentrate on articulatory issues which might lead to the innovation ('actuation') of change (or to its incrementation). MACKENZIE focuses on the innovation of constraints on sociolinguistic variables, also considering aspects of their propagation. STEVENS, HARRINGTON \& SCHIEL focus on propagation, and the way in which innovations can be taken up by a speech community. ECKERT focuses on aspects of social

6 The point is of clear conceptual importance for our topic: if change can't occur in individuals because language change only happens (by definition) in communities, then the role of individuals in change will (by definition) be less likely to be important than if language (by definition) exists in individuals. ECKERT does not exclude innovation as uninteresting, but comes close to the first position here when she writes that she adopts "the extreme proposal that change spreads by virtue of its role in a system of social meaning. And since individuals cannot construct meaning on their own, they can play no elemental role in sound change."

$7 \quad$ To consider only the Labovian panoply of relevant concepts and terms, for example, (bringing in some from Weinreich, Labov \& Herzog 1968), we would also need - if we were to be comprehensive - to consider constraints on change, the transition problem, and the embedding, evaluation and incrementation of change; we could also consider the exaggeration of phonetic variation (in the sense of Hyman 1976), and the enhancement and/or selection of variants (in line with Garrett \& Johnson 2013); in principle, individual differences could play out in any or none of these things.

8 DEDIU \& MOISIK further assume that, if most people in a particular group happen to have the same articulatory bias, that group may be more prone to certain types of sound change in a way that links both innovation and propagation (in that it is both more likely for particular types of change to be innovated and to be propagated in that group). 
theory most relevant to understanding propagation, as does DODSWORTH, concentrating on the role that interaction between speakers in social networks might play. BERMÚDEZ-OTERO combines a consideration of innovation and propagation, mainly focusing on the latter, and arguing that the two differ in their potential susceptibility to the effect of individual differences.

As a final facet to this section, we can ask: to what extent has previous work on sound change considered the extent to which differences between the individuals who make up a speech community might matter (or be decisive) in influencing when a change occurs? We will briefly consider three influential models of aspects of change: (i) the modular explanation of the existence of neogrammarian sound change, (ii) Ohala's theory of phonetic innovation, and (iii) Labov's account of propagation. By (i), we mean the idea that the fact that some changes are implemented in neogrammarian fashion (while others are not) can be understood to reflect what has been called the 'double articulation' of language: that is, the idea that phonological representations consist of recurring discrete categories whose realization in continuous phonetic space is assigned by rule (Paul 1886: 62; Bloomfield 1933: 364-365). By (ii), we mean Ohala's (1981, 1989) account of innovation as perceptual hypo- and hyper-correction, aiming to avoid teleology and make falsifiable predictions about the relative frequency with which different types of sound change are attested in the history of languages. And by (iii), we mean the decades of sociolinguistic research inspired by Labov, which have demonstrated that the propagation of change through a speech community involves orderly shifts in the frequency of competing variants along demographic dimensions such as age, gender, and social class (Labov 2001).

These models resemble one another in significant ways. First, none seeks to explain why phenomena are innovated in a particular location at a particular time; rather, all of them set out principles from which we can deduce general statements about sound change. Secondly, each account addresses itself to a specific facet of the problem: e.g. how change is implemented on the phonetic and lexical dimensions, how innovations first appear, or how they propagate. In this sense, all these models presuppose a certain division of labor in the explanation of sound change. Thirdly, the three theories concern themselves with macroscopic facts: i.e., they seek to explain generalizations about phenomena that can be observed either crosslinguistically with the tools of the typologist, or in the history of whole languages with the tools of philology, or at the level of the speech community with the tools of classical variationist sociolinguistics.

In turn, the proposed explanations depend on claims about a wide range of domains, including physical law, physiology, cognition, and the structure of human societies. Notably, all of these explanatory models abstract away from differences between individual speakers, focusing instead either on invariant factors (e.g. physical law, the architecture of mental grammars) or on broad demographic categories. Are they right to do so? The next section considers the notion of individual differences in detail, and shows how we can consider the ways in which individuals and the differences between them might be thought to be relevant to understanding sound change.

\section{What are 'individual differences'?}

This Special Collection necessitates an explicit focus on what we mean by individual differences. Our focus on sound change further calls to mind work on the role of the individual speakerlistener vis-à-vis the wider speech community, an issue which is related to, but not the same as, the role of individual differences. The diversity in theoretical perspectives represented in this Special Collection presents an opportunity to propose a broad, yet focused, interpretation of individual differences, an interpretation which we believe can offer a more fruitful and interdisciplinary understanding of the concept for research on individual differences beyond the study of sound change.

Individual differences superficially refer to factors about the speaker that are not otherwise represented in the analysis as group-level differences. The term has been common parlance in the field of psychology since at least the mid-1800s, especially in early anthropological studies of phrenology from around the same time (e.g., Owen 1850, Ecker 1868). In all cases, individual differences referred to any within-group differences that were not clearly explainable by other group-level factors. ${ }^{9}$ During the 20th and 21st centuries, research on individual

9 The clearest of these is probably a chapter from Dunglison (1850:648), entitled, "Individual Differences Amongst Mankind" in the book, Human Physiology. 
differences became distinctly associated with research in differential psychology, with work in anthropology, sociology, and other approaches to psychology being more characterized by a focus on group-level variation. Within differential psychology, individual differences might refer to any range of cognitive, behavioral, social, physiological, or genetic traits, depending on the particular research focus. Whatever the focus, the epistemic distinction between work on individual differences and work on group differences is the treatment of within-group variance as either the direct object of study or statistical noise.

Linguistic research on individual differences aligns with this work, in some cases being more specific, in others being more general. The 1979 volume Individual Differences in Language Ability and Language Behavior frames all "heterogeneity in language" in terms of individual differences (Fillmore, Kempler \& Wang 1979: xiii). The goal of the volume was "to learn how [linguistic performance] differences could be seen as relating to social, psychological, or biological parameters" (Fillmore et al., 1979: 1), aiming to raise the question as something that linguists should focus on. Some of the contributions to that volume point out that linguists had described individual linguistic differences before (including, notably, Sapir (1938)), but that there had been little continuity in such work up till the point at which the volume appeared. We can recognize now that this lack of continuity (and cumulativity) in research on individual differences in language in fact continued until relatively recently, only really becoming a serious subject of study in linguistics in the current century.

Studies focusing on language processing and speech perception have been particularly interested in variability framed as individual differences in terms of cognitive processing style (Yu \& Zellou 2019). Psycholinguistic research has demonstrated that individual speakers display consistent and stable differences from one another in, e.g. the amount of gradience exhibited in phonemic categorization tasks (Kong \& Edwards 2016), susceptibility to the Ganong effect (Stewart \& Ota 2008), reliance on top-down lexical information when parsing acoustically degraded speech (Ishida et al. 2016), compensation for coarticulatory effects in speech perception (Yu 2010, 2013), and neuronal response (Yu 2021). Work on language acquisition has identified individual differences "in every linguistic domain" (Kidd \& Donnelly 2020: 332). In the processing domain this includes speed, word segmentation, and phoneme discrimination. With respect to the production-perception link, researchers have considered individual differences in phonetic imitation (e.g., Chartrand \& Bargh 1999; Yu et al., 2013).

Such individual differences in speech processing styles have been hypothesized to correlate with differences in more general cognitive characteristics, including executive function capacity (Miyake et al. 2000), declarative versus procedural learning abilities (Ullman 2004), and autistic traits as measured by the Autism-Spectrum Quotient (AQ: Baron-Cohen et al. 2001). Chartrand \& Bargh (1999) consider individual differences in terms of individual empathy, and Yu (2013) considers personality, working memory capacity, and cognitive processing style. Lee \& Tomblin (2015) report that individuals with poor language abilities (including those with a history of language impairment) tend to perform worse than individuals with typical language skills in tasks assessing different forms of procedural learning. While much research in language acquisition considers environmental factors, many measures of individual difference are also cognitive (e.g., working memory, statistical learning; Kidd \& Donnelly 2020).

AQ scores have proved to be particularly good predictors of individual differences in auditory speech processing, in line with the general observation that young adults with Autism Spectrum Disorder exhibit increased auditory perceptual capacity when compared with neurotypical controls (Remington \& Fairnie 2017). Low AQ scores correlate with lesser sensitivity to implicit prosodic boundaries in syntactic parsing (Jun \& Bishop 2015), greater susceptibility to the Ganong effect (Stewart \& Ota 2008), and less perceptual compensation for coarticulation, particularly among women (Yu 2010, 2013). Of course, we cannot expect that all individual cognitive difference dimensions will necessarily be relevant to all dimensions of speech or language. It seems clear that they are not: for example, Kong \& Edwards (2016) did not find a correlation between gradience in phonemic categorization and measures of executive function capacity in all tasks, and Kuhn et al. (2014) found that early language skills were themselves a predictor of latter executive function skills. Understanding why some measures may turn out to be relevant but others may not is itself an important goal. 
In some cases, it is unclear if individual difference effects are attributable to cognitive processing styles, more specific linguistic differences, or something in between. At least some differences in speech perception may be a result of some listeners being "better phonetic perceivers" who are better equipped to extract and process acoustic-phonetic information. This idea is supported by a number of studies showing that differences in perceptual cue weights - measures of the diagnostic importance of different acoustic dimensions relevant for perception of a speech category - may be positively correlated both within and across contrasts (Hazan \& Rosen, 1991; Clayards, 2018; Jiang, Clayards, \& Sonderegger, 2020). Another area of interest is "superior processing of lexical tones in musicians" (Yu \& Zellou, 2019: 136; see Chandrasekaran et al. 2009, Wong \& Perrachione 2007). The extent to which these findings are explained by differences in perceptual acuity, a more general aptitude for speech processing, or more general cognitive abilities remains an open question.

One motivation for considering individual differences in the study of sound change comes from instances of phonetic and phonological variation that fail to correlate with traditional social group distinctions. For example, Ellis and Hardcastle (2002) find differences in the realization of British English /n\#k/ clusters unrelated to speaker dialect background. Mielke et al.'s (2016; see also SMith, Mielke, Magloughlin \& Wilbanks) ultrasound study of American English $/ \mathrm{x} /$ documents a wide range of allophonic patterns, often highly complex and speakerspecific, which may reflect both individual acquisition trajectories and individual articulatory motivations. Indeed, research now shows that between-talker variability is ubiquitous: to take just one well-studied example, voice onset time (VOT), a cross-linguistically important cue for the perception of laryngeal contrasts, varies systematically between talkers (Allen, Miller \& DeSteno, 2003). Importantly, the fact that mean VOT varies across talkers, but is correlated across place of articulation within the speech of an individual talker (Chodroff \& Wilson, 2017), indicates that this variability is structured rather than merely random, potentially due to differences in physiology or canonical speaking style between talkers.

The pursuit of new operational measures of individual differences thus results in the creation of (new) group-level differences. For example, Chandrasekaran, et al. (2009: 1)'s study contrasts "English musicians, English non-musicians, and native Chinese." Chartrand \& Baugh (1999: 905) created two participant groups based on composite responses to questions about perspective-taking, resulting in a "high-empathic-concern category" and a "low-empathicconcern category." Stewart \& Ota (2008) represent participants based on their Autism-Spectrum Quotient, and scores on other cognitive diagnostics. In each case, the superficial definition of individual differences as distinctly individual is therefore supplanted by new group-level differences introduced in an attempt to account for the variance not explained by more typical group-level differences. So, a quantitative vector like speaker 'ethnic identification' might be framed as a group-level difference in one study but as an individual difference in another study.

This is most apparent in linguistic studies that account for variation between individuals in terms of what a sociolinguist would call a group factor. Rubin's studies of reverse linguistic stereotyping, for example, frame individual differences in terms of the amount of exposure to different languages and cultures (Kang \& Rubin 2009). Work on language acquisition has divided individual differences into genetic and environmental factors, the former including biological sex and the latter including socioeconomic status (Kidd \& Donnelly 2020). Work on second language pronunciation has examined factors such as an individual's length of residence in an L1 context, and their "extent of L1 and L2 use, language learning context, gender and ethnic/ peer identification" (Edwards 2017: 385). In this way, some of the group-level factors that other linguists might describe as social factors may be framed instead as individual differences.

Variationist sociolinguistics in fact developed in parallel to the psychological strand of research on individual differences, focusing on operationalizing 'classic' group-level factors like gender, age, social class, and ethnicity. In many cases, these factors blur the line between the social and the cognitive. Drawing on insights from anthropology and critical studies, this body of work has operationalized social group membership based on ecologically valid categorization schemes. For example, the rise of the Communities of Practice model (Lave \& Wenger 1991; Eckert 2000) showcased how linguistic variation may be better modeled by group membership based on speakers' shared social practices, rather than their membership in demographic categories. While some of these social practices are strictly social (e.g., sartorial choices), others seem to 
quite closely reflect the same cognitive or personality distinctions that have been elsewhere framed as individual differences. Eckert (1989: 259), for example, shows how the trajectory of a sound change in progress (the Northern Cities Vowel Shift) is predicted by speaker orientations towards being "friendly, outgoing" on the one hand or "tough" on the other. In such cases, the cognitive factors typically discussed as individual differences may resemble those social factors that incorporate personality traits. This may appear to be the case in sociophonetic research that frames a variant's social meaning with respect to personae, or ideologized social types (e.g., yuppie), rather than macrosocial groups (e.g., middle class). However, a persona "is not an individual but an individual's expression of connection to the social landscape" (Eckert, to appear). This is altogether different from any usual notion of individual differences, being neither about individuals nor groups but about a rather different level of abstraction (see ECKERT). This particular sociolinguistic perspective argues that factors such as a speaker's expression of emotion are "best viewed as an interactional accomplishment rather than an inner psychological state" (Podesva et al. 2015: 4; see also Goodwin et al. 2012). In short, the argument is that socalled individual differences are not individual differences at all.

Nonetheless, sociophonetic studies of sound change do discuss individual speakers (see Yu \& Zellou 2019: 142-144). For example, Tamminga (2019) considers whether some individuals are more likely than others to lead in ongoing sound changes, using a sociolinguistically collected corpus of Philadelphia English speech. She finds that speakers who lead in the propagation of one particular change in a community do not necessarily lead other changes taking place at the same time in the same community. This fits with previous related work, such as Waters \& Tagliamonte (2017), who make a similar finding for non-phonological ongoing changes, showing a skepticism about the consistency of potential individual differences in this area about whether some individuals are more likely overall to behave as a propagator (or even innovator) in change.

Clearly, there is a fundamental difference between explaining the role of individual differences in sound change and the role of the individual in sound change. While the former considers the predictive power of factors related to individual cognition, personality, and social position, the latter essentially considers the relative predictive power of outliers versus inliers: leaders of change, and their followers. This is not necessarily a consideration of individual differences, since such an analysis may focus entirely on an individual's position in a social network, which may be framed more as a property of the whole rather than a property of the individual (e.g., Kauhanen 2017; DODSWORTH).

Work on the role of the individual is, however, often framed in terms of an individual speaker's personal manifestation of those factors typically considered to be individual differences. Labov (1979), for example, describes cases of variation, change, and acquisition of New York City and Philadelphia Englishes where "we have reached the limits of the social determination of linguistic behavior, and have touched on psychological differences within the group" (330), focusing on individual speakers who diverge from group patterns. While in many of these cases "individual differences in psychological orientation have led to differences in social experience and social aspirations, which in turn are reflected in predictable, socially patterned differences in behavior," (330-331) in other cases he identifies cognitive differences in speakers' "sensitivity or insensitivity to the rules of other dialects, or the capacity to modify a vernacular pattern when exposed to other patterns" (332). Labov's orientation to "individual differences in cognitive style" is focused on the ability to analytically "isolate psychological parameters from social history" and to look at specific cases of particular individuals for clues to what relevant cognitive factors might further account for patterns of linguistic variation within social groups (335).

Current approaches to research on individual differences are broad and wide-ranging. In the context of this Special Collection, we conceive of individual differences as being any differences related to individual speakers that cannot be considered as purely demographic factors. Among the papers in the current collection, two consider articulatory variability. DEDIU \& MoISIK consider tongue posture with respect to vocal tract anatomy, and SMITH, MIELKE, MAGLOUghlin \& WilBANKS examine tongue posture along with lip-rounding. MACKENZIE discusses individual differences in representation and speech production planning, and YU focuses directly on representation by considering individual differences in phonologization. All 
four of these papers argue in favor of a role for individual differences in explaining key aspects of sound change.

In contrast, three other papers focus on differences between individuals rather than what are elsewhere called individual differences. The focus here is on the role of individual speakers' production of the sound changes themselves, rather than on some other measure that is then correlated with variant realization. This perspective engages with previous literature, for example, on exceptional speakers: innovators, leaders, and other statistical outliers. All three papers argue against an explanatory role for differences between individuals. STEVENS, HARRINGTON \& SCHIEL argue that the differences between individuals that appear in their models are not germane to the forces driving the sound change, even when those differences manifest as certain individual speakers exerting more influence than other speakers. Similarly, BERMÚDEZ-OTERO argues that, while the innovations themselves can be understood at an individual level, the propagation of change is necessarily only at the level of the community. Interestingly, this is similar to the argument put forth in ECKERT's paper, despite the fact that her paper argues that social meaning is central to explaining sound change while BERMúDEZOTERO contends that its role is decidedly peripheral. ECKERT argues that an individual difference (of the more general sort) will only influence the spread of a sound change when it is no longer tied to particular individuals.

DODSWORTH's paper is uniquely situated between these two approaches. Her work theorizes individual differences as different "positions in the community network structure," operationalized via bipartite networks, or the social proximity between individuals (as opposed to the ego-centric approach to social networks seen in most sociolinguistic work). But while she operationalizes individual differences as a community-level characteristic, DoDSwORTH also examines individual members and individual dyads within a community network, and argues that variable orientations to variants' social meanings explain "exceptional" behavior in phonetic production and are, thus, important for sound change research.

\section{Synthesis: making progress in the study of individual differences and sound change}

As the previous sections have made clear, different scholars and traditions approach sound change and individual differences in different ways. Section 3 highlighted the conceptual and terminological differences in what constitutes '(sound) change', pointing out that for some scholars, 'change' is inherently something that takes place in individuals, while for others, 'change' is by definition something that can only occur at the level of the speech community. Section 4 draws a critical distinction between individuals and individual differences, noting that individual differences are often really group-level properties similar to the traditional sociolinguistic variable, while pointing out that discussions of the role of 'the individual' in sound change studies will often focus on the position of that individual in a community structure, rather than on intrinsic properties of the individuals themselves.

In situating the papers in this Special Collection in the broader scholarship, it is worth reminding ourselves of how and why different linguistic subfields engage with the study of sound change. Classical historical-comparative linguistics is typically concerned with producing reconstructions for the goal of determining genetic relatedness. It is the regularity of change, rather than its underlying cause or phonetic basis, that is ultimately most critical for this enterprise. ${ }^{10}$ Phonologists, historically-minded or otherwise, are often interested in matters of typology ('what is a possible sound-system?'), which leads naturally to considerations of how changes to such systems might be constrained ('what is a possible sound change?'). Phoneticians and psycholinguists typically work more directly with acoustic, articulatory, auditory, and/or visual records of speech, not only in an effort to understand their inherent properties, but also to understand how they might be influenced by more 'domain-general' aspects of human physiology and cognition. Much work on sound change in these areas has focused on empirical demonstrations of physiological and/ or cognitive factors which might underpin frequently observed sound changes and/or patterns.

10 While phonetic realism or 'naturalness' in reconstructions is certainly deemed to be a useful principle, in practice it is often trumped by regularity: "[t] he naturalness principle is applicable only if there is a choice between competing analyses" (Hock, 1991: 548). 
Finally, (variationist) sociolinguistics takes the insights of all of these areas as its foundation, inasmuch as notions like naturalness, structure, and function play a role in determining which phonetic variables are selected for sociolinguistic marking. However, the primary concern of many sociolinguists has been to understand the factors which influence how variables generalize, both throughout the lexicon and throughout the speech community.

The study of intrinsic properties of individuals is not uncommon in phonetics and psycholinguistics, regardless of whether or not sound change is in focus. On the other hand, while one cannot imagine most historians or sociolinguists denying that individuals vary in their cognitive, physiological, and/or psychological properties, it is not clear that the existence of such differences is always useful to understanding the central research questions of those fields (cf. Section 4), due perhaps in part to the time scales that are typically involved. ${ }^{11}$ We may also note that, to the extent that they constitute relatively autonomous (sub)fields of study, historical linguistics and sociolinguistics have the study of (sound) change at their very core; while phonetics and phonology, for better or for worse, have often been approached from the perspective of synchronic idealization.

It is also worth considering the historical context in which the study of sound change (and language change more broadly) has developed. The perspectives outlined in Weinreich, Labov \& Herzog's landmark 1968 study have had a significant influence on the directions pursued in a great deal of subsequent sound change research. A large portion of Weinreich et al. is given over to trenchant criticism of earlier approaches to the study of sound change. As the authors make clear, both the Neogrammarians and the American Structuralists seemed to deny the very possibility of ever observing sound change in progress, a conundrum aptly illustrated by this "elegantly baffled" passage from Hockett (1958):

"Sound change itself is constant and slow. A phonemic restructuring, on the other hand, must in a sense be absolutely sudden. No matter how gradual was the approach of early M[iddle] E[nglish] /ǽ/ and /’́/ towards each other, we cannot imagine the actual coalescence of the two other than as a sudden event: on such-and-such a day, for such-and-such a speaker or tiny group of speakers, the two fell together as /á/ and the whole system of stressed nuclei, for the particular idiolect or idiolects, was restructured.

Yet there is no reason to believe that we would ever be able to detect this kind of sudden event by direct observation..." (1958: 456-457; emphasis in original)

Since Weinreich et al. were (quite rightly, on our view) concerned with putting the study of sound change on a firmly empirical basis, it follows that, if both gradual and abrupt changes are unobservable, then the empirical study of language change is de facto impossible. Thus, the impetus to shift the locus of study to something that would even be possible to observe, measure, and quantify was a matter of theoretical necessity as much as it was about taking a position on what 'sound change' means. This was without a doubt a sensible move, especially when viewed in its proper historical context; nevertheless, as noted by Garrett (2015), researchers now have access to a range of methods and data that were simply not available in the 1960s. Studies such as those of SMith, Mielke, Magloughlin \& Wilbanks or Dediu \& Moisik exploit modern instrumental techniques and highly detailed databases of individual traits, while those by DODSWORTH and STEVENS, HARRINGTON \& SCHIEL leverage the kinds of computational resources which are commonplace today but which were scarcely imaginable 50 years ago. The alleged unobservability of change at the level of the individual that seemed so inescapable to Hockett (and which Weinreich and colleagues also seem to have accepted as a basic fact) may thus no longer be sufficient grounds for excluding the study of the role of the individual in sound change tout court.

Of course, as mentioned above, the Labovian tradition has always recognized the role of low-level variation in generating variants which may acquire social significance. However,

11 For example, Weinreich, Labov \& Herzog (1968) define "long-term changes" as being on the order of millenia, "completed changes" on the order of centuries and "ongoing" changes as those taking place within the past 1-2 generations. Note that there are, of course, countless studies in sociolinguistics that take a closer look at certain individuals, sometimes also with respect to cognitive or psychological properties (e.g., Hall-Lew 2013), but these properties are typically taken as accounting for the individual's position in the wider system; a proof-of-concept, rather than evidence for a causal role. 
one question that seems to have gone largely unaddressed in this tradition is the following: what makes one pronunciation variant more likely to be selected for sociolinguistic marking than another? Hock (1991: 653-4) suggests variable selection might be favored by relative imperceptibility and absence of non-phonetic (or non-phonological) marking, factors which strike us as consistent with Labov's proposal that misperceived (in his terms, 'misunderstood') tokens are rejected by listeners, i.e. would not influence the mean of the 'exemplar cloud' (1994: 586ff.). The influence of relative (im)perceptibility in particular seems likely to be affected by intrinsic properties of individuals (see e.g. Beddor 2012 on individual differences in the degree of perceptual adjustment, the work of Clayards and colleagues referenced in Section 4, as well as the papers by Dediu \& MoisiK, SMith, MielKe, MAgloughlin \& Wilbanks, and YU in this Collection), and this suggests at least one possible area where studies of individuallevel properties might interface with the general Labovian approach. From that perspective, Milroy (2007) approaches the question by distinguishing between 'off the shelf' and 'under the counter' variants. The former "have greater social and cognitive accessibility" (2007: 160), "for a number of different reasons, which might be social, structural or perceptual" (2007: 163). The latter are less accessible and "usually assumed to be phonetically and phonologically simple" (2007: 162), although this is not necessarily the reason for their lack of perceptual salience. For our purposes, the key observation is that some ('under the counter') variants spread via individuals' network ties, whereas other ('off the shelf') variants spread regardless of the structure of an individual's social network.

The framing of individual differences in terms of their social network structures is but one reflection of the "central dogma" of variationist sociolinguistics that "the individual is not a unit of linguistic analysis" (Labov 2011: 7), a position carried forwards here by ECKERT and to a certain extent BERMÚDEZ-OTERO. While Weinreich, Labov \& Herzog effectively made being able to coherently pose the 'actuation problem' a requirement for any empirical approach to studying change, their understanding of actuation is as something taking place at the level of the speech community, rather than a change occurring in the grammar of a single individual.

We do not see these approaches as being incommensurable, and hope that this discussion prompts scholars working in diverse areas to think about how and where their work fits into the larger arc of studying sound change, from innovation (initiation, actuation) through to propagation (transmission, diffusion). This conception of the sociolinguistic and psychological/ phonetic approaches being ultimately two parts of a single whole is well expressed by Garrett (2015):

"In the end the [social and psychological] approaches must be linked, since language is learned and known by individuals but used in social interaction. Every change must originate with individuals, but if it is to be observed it must diffuse in a speech community." (2015: 242)

While Garrett's quote may seem self-evident, as shown by the diversity of views showcased in this Special Collection (and discussed in Section 3), even this position is unlikely to enjoy universal agreement: if language is by definition a social phenomenon, what does it mean for it to be learned and known by individuals? Is diffusion truly a prerequisite to observing change in progress, or is it now possible to see evidence for changes taking place within an individual? We hope that this Special Collection will serve as a point of departure for continued discussion and debate of these ideas in the years to come.

\section{Acknowledgements}

We would like to thank all those who attended the Fourth International Workshop on Sound Change at the University of Edinburgh (which was the starting point for this Special Collection), the authors of the articles in the collection (several of whom gave us helpful comments on this introduction), all those at Glossa who helped us with the collection, and especially the reviewers who commented on the articles in the collection as they developed. We also owe special thanks to Ricardo Bermúdez-Otero, who generously donated several paragraphs of thoughts which have been worked into sections of the text of this piece. 


\section{Competing interests}

The authors have no competing interests to declare.
Hall-Lew et al.

Glossa: a journal of

general linguistics

DOI: $10.5334 /$ gjgl.1630

\section{Author affiliations}

\section{Lauren Hall-Lew}

University of Edinburgh 3 Charles St., Edinburgh, EH8 9AD, GB

\section{Patrick Honeybone}

University of Edinburgh 3 Charles St., Edinburgh, EH8 9AD, GB

\section{James Kirby}

University of Edinburgh 3 Charles St., Edinburgh, EH8 9AD, GB

\section{References}

Allen, J. Sean, Joanne L. Miller \& David DeSteno. 2003. Individual talker differences in voiceonset-time. The Journal of the Acoustical Society of America 113(1). 544-552. DOI: https://doi. org/10.1121/1.1528172

Baker, Adam, Diana Archangeli \& Jeff Mielke. 2011. Variability in American English s-retraction suggests a solution to the actuation problem. Language Variation and Change 23(3). 347-374. DOI: https://doi. org/10.1017/S0954394511000135

Baron-Cohen, Simon, Sally Wheelwright, Richard Skinner, Joanne Martin \& Emma Clubley. 2001. The autism-spectrum quotient (AQ): Evidence from asperger syndrome/high-functioning autism, males and females, scientists and mathematicians. Journal of autism and developmental disorders 31(1). 5-17. DOI: https://doi.org/10.1023/A:1005653411471

Beddor, Patrice Speeter. 2012. Perception grammars and sound change. In Maria-Josep Solé \& Daniel Recasens (eds.) The initiation of sound change: Perception, production, and social factors, 37-56. Amsterdam: John Benjamins. DOI: https://doi.org/10.1075/cilt.323.06bed

Bermúdez-Otero, Ricardo. 2015. Amphichronic explanation and the life cycle of phonological processes. In Patrick Honeybone \& Joseph C. Salmons (eds.) The Oxford Handbook of Historical Phonology, 374 399. Oxford: Oxford University Press.

Bloomfield, Leonard. 1933. Language. New York: Holt.

Bybee, Joan. 2002a. Lexical diffusion in regular sound change. In David Restle \& Dietmar Zaefferer (eds.) Sounds and Systems: Studies in Structure and Change. Berlin: Mouton de Gruyter. 58-74.

Bybee, Joan. 2002b. Word frequency and context of use in the lexical diffusion of phonetically conditioned sound change. Language Variation and Change 14(3). 261-290. DOI: https://doi. org/10.1017/S0954394502143018

Chandrasekaran, Bharath, Ananthanarayan Krishnan \& Jackson T. Gandour. 2009. Relative influence of musical and linguistic experience on early cortical processing of pitch contours. Brain and Language 108(1). 1-9. DOI: https://doi.org/10.1016/j.bandl.2008.02.001

Chartrand, Tanya L. \& John A. Bargh, 1999. The chameleon effect: the perception-behavior link and social interaction. Journal of Personality and Social Psychology 76. 893-910. DOI: https://doi. org/10.1037/0022-3514.76.6.893

Chodroff, Eleanor \& Colin Wilson. 2017. Structure in talker-specific phonetic realization: Covariation of stop consonant VOT in American English. Journal of Phonetics 61. 30-47. DOI: https://doi. org/10.1016/j.wocn.2017.01.001

Clayards, Meghan. 2018. Differences in cue weights for speech perception are correlated for individuals within and across contrasts. The Journal of the Acoustical Society of America 144. EL172-177. DOI: https://doi.org/10.1121/1.5052025

Croft, William. 2000. Explaining Language Change: An Evolutionary Approach. Harlow: Longman.

Dunglison, Robley. 1850. Human physiology. 2. Lea and Blanchard. DOI: https://doi.org/10.5962/bhl. title.21373

Ecker, Alexander. 1868. On a Characteristic Peculiarity in the Form of the Female Skull, and Its Significance for Comparative Anthropology. The Anthropological Review 6(23). 350-356. DOI: https:// doi.org/10.2307/3025024

Eckert, Penelope. 1989. Jocks and burnouts: Social categories and identity in the high school. Teachers College Press.

Eckert, Penelope. 2000. Language Variation as Social Practice. Oxford, UK: Blackwell.

Eckert, Penelope. to appear 2021. Afterword. In Lauren Hall-Lew, Emma Moore \& Robert J. Podesva (eds.), Social Meaning and Linguistic Variation: Theorizing the Third Wave, 382-387. Cambridge: Cambridge University Press. 
Edwards, Jette G. Hansen. 2017. Pronunciation and individual differences. In Okim Kang, Ron I. Thomson \& John M. Murphy (eds.), The Routledge Handbook of Contemporary English Pronunciation, 385-398. London and New York: Routledge. DOI: https://doi.org/10.4324/9781315145006-24

Fillmore, Charles J., Daniel Kempler \& William S.-Y. Yang (eds.). 1979. Individual differences in language ability and language behavior. New York, NY: Academic Press.

Garrett, Andrew. 2015. Sound change. In Bowern, C. \& Evans, B. (eds.), The Routledge Handbook of Historical Linguistics, 227-248. London and New York: Routledge.

Garrett, Andrew \& Keith Johnson. 2013. Phonetic bias in sound change. In Alan Yu (ed.), Origins of Sound Change: Approaches to Phonologization, 51-97. Oxford: Oxford University Press. DOI: https:// doi.org/10.1093/acprof:oso/9780199573745.003.0003

Goodwin, Marjorie H., Asta Cekaite, Charles Goodwin \& E. Tulbert. 2012. Emotion as stance. In Anssi Peräkylä \& Marja-Leena Sorjonen (eds.). Emotion in interaction, 16-41. New York and Oxford: Oxford University Press. DOI: https://doi.org/10.1093/acprof:oso/9780199730735.003.0002

Hale, Mark. 2007. Historical Linguistics: Theory and Method. Oxford: Blackwell.

Hall-Lew, Lauren. 2013. 'Flip-flop' and mergers-in-progress. English Language and Linguistics 17(2). 359390. DOI: $h$ ttps://doi.org/10.1017/S1360674313000063

Hansson, Gunnar Ólafur. 2008. Diachronic explanations of sound patterns. Language and Linguistics Compass 2(5). 859-893. DOI: https://doi.org/10.1111/j.1749-818X.2008.00077.x

Hazan, Valerie \& Stuart Rosen. 1991. Individual variability in the perception of cues to place contrasts in initial stops. Perception \& Psychophysics 49. 187-200. DOI: https://doi.org/10.3758/BF03205038

Hill, Eugen. 2019. Prosodic change and the (apparent) irregularities in the development of segments. Folia Linguistica Historica 40. 323-353. DOI: https://doi.org/10.1515/flih-2019-0014

Hock, Hans Heinrich. 1991. Principles of historical linguistics. Berlin: Mouton de Gruyter. DOI: https://doi. org/10.1515/9783110219135

Hockett, Charles. 1958. A course in modern linguistics. New York: MacMillan.

Honeybone, Patrick. 2016. Are there impossible changes? $\theta>\mathrm{f}$ but $\mathrm{f} \ngtr \theta$. Papers in Historical Phonology 1. 316-358. DOI: https://doi.org/10.2218/pihph.1.2016.1705

Hyman, Larry. 1976. Phonologization. In Alphonse Juilland (ed.), Linguistic Studies offered to Joseph Greenberg, 2. 407-418. Saratoga: Anma Libri.

Ishida, Mako, Arthur G. Samuel \& Takayuki Arai. 2016. Some people are 'More Lexical' than others. Cognition 151. 68-75. DOI: https://doi.org/10.1016/j.cognition.2016.03.008

Janda, Richard D. \& Brian D. Joseph. 2003. Reconsidering the canons of sound change: towards a Big Bang Theory. In Barry J. Blake \& Kate Burridge (eds.) Historical Linguistics, 205-219. Amsterdam: John Benjamins. DOI: https://doi.org/10.1075/cilt.237.14jan

Jiang, Bing'er, Meghan Clayards \& Morgan Sonderegger. 2020. Individual and dialect differences in perceiving multiple cues: A tonal register contrast in two Chinese Wu dialects. Laboratory Phonology 11(1). 1-30. DOI: https://doi.org/10.5334/labphon.266

Jones, Mark. J. 2015. Individuals, Innovation, and Change. In Patrick Honeybone \& Joseph Salmons (eds.) The Oxford Handbook of Historical Phonology, 400-409. Oxford: Oxford University Press. DOI: https://doi.org/10.1093/oxfordhb/9780199232819.013.013

Jun, Sun-Ah \& Jason Bishop. 2015. Priming implicit prosody: prosodic boundaries and individual differences. Language and speech, 1-15. DOI: https://doi.org/10.1177/0023830914563368

Kang, Okim \& Donald L. Rubin. 2009. Expectations on Speech Evaluation Reverse Linguistic Stereotyping: Measuring the Effect of Listener. Journal of Language and Social Psychology 28. 441-456. DOI: https:// doi.org/10.1177/0261927X09341950

Kauhanen, Henri. 2017. Neutral change. Journal of Linguistics 53(2). 327-358. DOI: https://doi. org/10.1017/S0022226716000141

Kidd, Evan \& Seamus Donnelly. 2020. Individual differences in first language acquisition. Annual Review of Linguistics 6. 319-340. DOI: https://doi.org/10.1146/annurev-linguistics-011619-030326

King, Robert Desmond. 1969. Historical Linguistics and Generative Grammar. Englewood Cliffs: Prentice-Hall.

Kong, Eun Jong \& Jan Edwards. 2016. Individual differences in categorical perception of speech: cue weighting and executive function. Journal of Phonetics 59(1). 40-57. DOI: https://doi.org/10.1016/j. wocn.2016.08.006

Kuhn, Laura J., Michael T. Willoughby, Makeba Parramore Wilbourn, Lynne Vernon-Feagans, Clancy B. Blair \& Family Life Project Key Investigators. 2014. Early communicative gestures prospectively predict language development and executive function in early childhood. Child Development 85(5). 1898-1914. DOI: https://doi.org/10.1111/cdev.12249

Labov, William. 1966. The social stratification of English in New York City. Washington, DC: Center for Applied Linguistics.

Labov, William. 1979. Locating the frontier between social and psychological factors in linguistic variation. In Charles J. Fillmore, Daniel Kempler \& William S.-Y. Yang (eds.), Individual differences in language ability and language behavior, 327-340. San Diego: Academic Press. DOI: https://doi. org/10.1016/B978-0-12-255950-1.50025-1 
Labov, William. 1994. Principles of linguistic change. Vol. 1: Internal factors. Oxford: Blackwell.

Labov, William. 2001. Principles of linguistic change, Vol. 2: Social factors. Oxford: Blackwell.

Labov, William. 2007. Transmission and Diffusion. Language 83. 344-387. DOI: https://doi.org/10.1353/ lan.2007.0082

Labov, William. 2011. Principles of Linguistic Change, Vol. 3: Cognitive and Cultural Factors. John Wiley \& Sons. DOI: https://doi.org/10.1002/9781444327496

Labov, William. 2020. The regularity of regular sound change. Language 96. 42-59. DOI: https://doi. org/10.1353/lan.2020.0001

Lass, Roger. 1997. Historical Linguistics and Language Change. Cambridge: Cambridge University Press. DOI: https://doi.org/10.1017/CBO9780511620928

Lave, Jean \& Etienne Wenger. 1991. Situated Learning: Legitimate Peripheral Participation. Cambridge: Cambridge University Press. DOI: https://doi.org/10.1017/CBO9780511815355

Lee, Joanna C. \& J. Bruce Tomblin. 2015. Procedural learning and individual differences in language. Language Learning and Development 11(3). 215-236. DOI: https://doi.org/10.1080/15475441.2014.904168

Mielke, Jeff, Adam Baker \& Diana Archangeli. 2016. Individual-level contact limits phonological complexity: evidence from bunched and retroflex /I/. Language 92(1). 101-140. DOI: https://doi. org/10.1353/lan.2016.0019

Milroy, James. 1992. Linguistic Variation and Change. Oxford: Blackwell.

Milroy, Lesley. 2007. Off the shelf or under the counter? On the social dynamics of sound changes. In Cristopher M. Cain \& Geoffrey Russom (eds.), Managing chaos: Strategies for identifying change in English. Studies in the history of the English Language III, 149-172. Berlin: Mouton de Gruyter. DOI: https://doi.org/10.1515/9783110198515.3.149

Miyake, Akira, Naomi P. Friedman, Michael J. Emerson, Alexander H. Witzki, Amy Howerter \& Tor D. Wager. 2000. The unity and diversity of executive functions and their contributions to complex 'frontal lobe' tasks: a latent variable analysis. Cognitive Psychology 41(1). 49-100. DOI: https://doi. org/10.1006/cogp.1999.0734

Ohala, John. 1981. The listener as a source of sound change. In Carrie Masek, Roberta Hendrick \& Mary Frances Miller (eds.), Papers from the parasession on language and behavior, 178-203. Chicago: Chicago Linguistic Society.

Ohala, John J. 1989. Sound change is drawn from a pool of synchronic variation. In Leiv Egil Breivek \& Ernst Håkon Jahr (eds.), Language change: contributions to the study of its causes, 173-198. Berlin: Mouton de Gruyter.

Owen, Richard. 1850. Observations on Three Skulls of Naloo Africans. Journal of the Ethnological Society of London (1848-1856) 2. 235-237. DOI: https://doi.org/10.2307/3014125

Paul, Hermann. 1886. Principien der Sprachgeschichte, 2nd edn. Halle: Max Niemeyer. 1st edn 1880.

Podesva, Robert J., Patrick Callier, Rob Voigt \& Dan Jurafsky. 2015. The connection between smiling and GOAT fronting: Embodied affect in sociophonetic variation. In The Scottish Consortium for ICPhS 2015 (ed.), Proceedings of the 18th International Congress of Phonetic Sciences. Glasgow, UK: the University of Glasgow. ISBN 978-0-85261-941-4. https://www.internationalphoneticassociation.org/ icphs-proceedings/ICPhS2015/Papers/ICPHS0343.pdf.

Remington, Anna \& Jake Fairnie. 2017. A sound advantage: increased auditory capacity in autism. Cognition 166, 459-465. DOI: https://doi.org/10.1016/j.cognition.2017.04.002

Ringe, Don \& Joseph F. Eska. 2013. Historical Linguistics: Toward a Twenty-First Century Reintegration. Cambridge: Cambridge University Press. DOI: https://doi.org/10.1017/CBO9780511980183

Salmons, Joseph. 2021. Sound change. Edinburgh: Edinburgh University Press.

Sankoff, Gillian \& Hélène Blondeau. 2007. Language change across the lifespan: /r/ in Montreal French. Language 83(3). 560-88. DOI: https://doi.org/10.1353/lan.2007.0106

Sapir, Edward. 1938. Why cultural anthropology needs the psychiatrist. Psychiatry 1. 7-12. [Reprinted in David G. Mandelbaum (ed.), 1968. Selected Writings of Edward Sapir. Berkeley: University of California Press, 569-577.] DOI: https://doi.org/10.1080/00332747.1938.11022170

Stevens, Mary \& Jonathan Harrington. 2014. The individual and the actuation of sound change. Loquens 1. e003. DOI: https://doi.org/10.3989/loquens.2014.003

Stewart, Mary E \& Mitsuhiko Ota. 2008. Lexical effects on speech perception in individuals with 'autistic' traits. Cognition 109. 157-162. DOI: https://doi.org/10.1016/j.cognition.2008.07.010

Tamminga, Meredith. 2019. Interspeaker covariation in Philadelphia vowel changes. Language Variation and Change 31(2). 119-133. DOI: https://doi.org/10.1017/S0954394519000139

Ullman, Michael T. 2004. Contributions of memory circuits to language: the declarative/procedural model. Cognition 92. 231-270. DOI: https://doi.org/10.1016/j.cognition.2003.10.008

Waters, Cathleen \& Sali A. Tagliamonte. 2017. Is one innovation enough? Leaders, covariation, and language change. American Speech 92(1). 23-40. DOI: https://doi.org/10.1215/00031283-4153186

Weinreich, Uriel, William Labov \& Marvin Herzog. 1968. Empirical Foundations for a Theory of Language Change. In Winfred P. Lehmann \& Yakov Malkiel (eds.), Directions for Historical Linguistics: A Symposium, 95-188. Austin: University of Texas Press. 
Wong, Patrick C. M. \& Tyler K. Perrachione. 2007. Learning pitch patterns in lexical identification by native English-speaking adults. Applied Psycholinguistics 28(4). 565-585. DOI: https://doi. org/10.1017/S0142716407070312

Yu, Alan C. L. 2013. Individual differences in socio-cognitive processing and sound change. In Alan C. L. Yu (ed.), Origins of Sound Change: Approaches to Phonologization, 201-227. Oxford: Oxford University Press. DOI: https://doi.org/10.1093/acprof:oso/9780199573745.003.0010

Yu, Alan C. L. 2021. New Ways of Analyzing Individual Variation. Plenary Address at New Ways of Analyzing Variation - Asia-Pacific, National University of Singapore (online).

Yu, Alan C. L. \& Georgia Zellou. 2019. Individual Differences in Language Processing: Phonology. Annual Review of Linguistics 5. 131-50. DOI: https://doi.org/10.1146/annurev-linguistics-011516-033815
Hall-Lew et al. Glossa: a journal of general linguistics

DOI: 10.5334 /gjgl.1630
TO CITE THIS ARTICLE: Hall-Lew, Lauren, Patrick Honeybone and James Kirby. 2021. Individuals, communities, and sound change: an introduction. Glossa: a journal of general linguistics 6(1): 67. 1-17. DOI: https://doi.org/10.5334/ gjgl.1630

Submitted: 11 March 2021 Accepted: 14 April 2021 Published: 17 May 2021

COPYRIGHT:

(c) 2021 The Author(s). This is an open-access article distributed under the terms of the Creative Commons Attribution 4.0 International License (CC-BY 4.0), which permits unrestricted use, distribution, and reproduction in any medium, provided the original author and source are credited. See http:// creativecommons.org/ licenses/by/4.0/.

Glossa: a journal of general linguistics is a peer-reviewed open access journal published by Ubiquity Press. 